\title{
Different connections with the core tube steel frame seismic performance of hybrid structure analysis
}

\author{
Chao Yang, Chengwei Huang, Ruofei Liu, Yi Tian \\ Architecture and Engineering, Kunming University of Science and Technology, Kunming, China \\ 1156659329@qq.com,994048762@qq.com,331652799@qq.com,1106268047@qq.com
}

Keywords: hybrid structure; seismic performance; dynamic characteristics; response spectrum analysis

Abstract: In this paper, a steel frame - core tube hybrid structure commercial building design as engineering background in Kunming, steel beam and the core tube using different connection methods affect the structure of the lateral performance. All hinged model established with some rigid model, modal analysis and response spectrum analysis, comparing its dynamic characteristics and performance of multi-lateral event of an earthquake under the analysis of the seismic performance in high intensity areas.

\section{Introduction}

In areas of high seismic fortification intensity, building height increases, the difficulty of structural seismic design increases. Steel is the direction of the development of high-rise buildings, but when the height is higher, due to the member section of pure steel is smaller, weaker lateral stiffness, strength under normal conditions are met, the lateral displacement of a large building, not meet the requirements of lateral stiffness, comfort is also poor. Thus, in the high-rise building structural system, the steel-concrete composite structure has been rapid development.

Steel frame - concrete core structural system made of steel tube frame and reinforced concrete core wall composed of steel frame structures bear most vertical loads, the concrete core wall as the main lateral force resisting member, resist most of the seismic loads and wind loads, resist overturning bend moment. Due to the presence of the core barrel, can transport, service area to focus on core tube arrangement, the structural arrangement flexible.

In this paper, the actual project in Kunming, the numerical simulation by finite element software SATWE and ETABS, analysis and research the seismic performance when frequently occurred earthquake.

\section{Structural Finite Element Model}

Finite element model of the structure-based design to engineering and construction, and a certain amount of simplification, without regard to the frame and the top of the steel structure of the peripheral edge, the edge of the frame weight and load conversion applied to the outer frame beam line load.

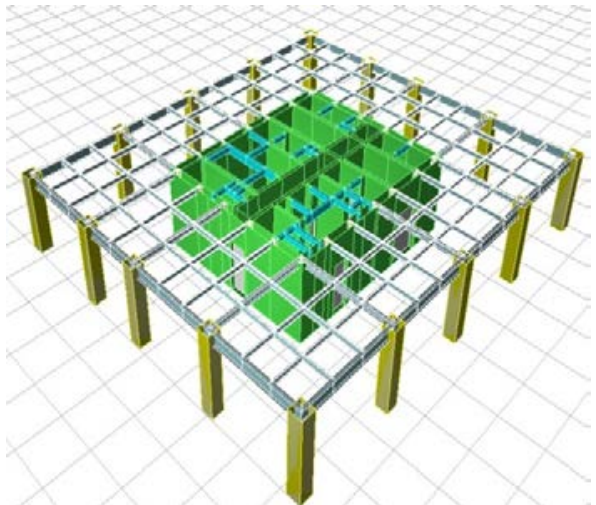

a) SATWE

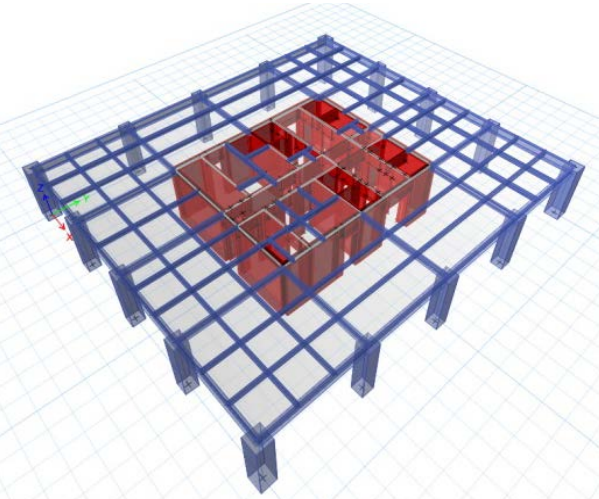

b)ETABS 
Frequently occurred during the earthquake seismic analysis, structural models should be consistent with the actual situation, to meet the requirements of carrying capacity and stiffness requirements. When ETABS modeling, shear walls using shell elements, coupling beams using an open-hole approach. Floor without considering the external surface stiffness, using membrane unit, but the definition in the calculation of the displacement of rigid bulkhead, equivalent to the rigid floor SATWE assumed to reduce structural degrees of freedom, to save computing time.

In the hybrid structure, floor beams and reinforced concrete cylinder connection can be rigid or articulated. Therefore, this paper established a model and part hinged rigid model of connection forms a comparison. Model is hinged steel beams and connections all core barrel hinge; part of the model is the core of rigid tube steel beams rigidly connected with the corner, and the rest is still hinged connection.

The following model will take the two different connection methods, its modal analysis and response spectrum analysis, comparing its dynamic characteristics and lateral performance.

\section{Dynamic Characteristics Analysis}

SATWE and ETABS were using modeling, computational basic dynamic characteristics before 18 vibration mode, both models floor steel beams and the core barrel all hinged models and floor steel beams rigidly connected with the core barrel part model are shown in Table 2.1 to Table 2.3.

Table 2.1 SATWE hinged model with some rigid model of the first six vibration mode cycle

\begin{tabular}{c|c|c|c|c|c|c|c|c}
\hline \multirow{2}{*}{ Modes } & \multicolumn{4}{|c|}{ Articulated Model } & \multicolumn{4}{c}{ Part of the Rigid Model } \\
\cline { 2 - 9 } & Cycle (s) & UX & UY & RZ & Cycle (s) & UX & UY & RZ \\
\hline 1 & 2.1695 & 1.00 & 0.00 & 0.00 & 2.0896 & 1.00 & 0.00 & 0.00 \\
\hline 2 & 1.9987 & 0.00 & 1.00 & 0.00 & 1.9489 & 0.00 & 1.00 & 0.00 \\
\hline 3 & 1.1364 & 0.00 & 0.00 & 1.00 & 1.2207 & 0.00 & 0.00 & 1.00 \\
\hline 4 & 0.5185 & 0.01 & 0.99 & 0.00 & 0.5353 & 0.17 & 0.83 & 0.00 \\
\hline 5 & 0.5107 & 0.99 & 0.01 & 0.00 & 0.5245 & 0.83 & 0.17 & 0.00 \\
\hline 6 & 0.4018 & 0.00 & 1.00 & 1.00 & 0.4327 & 0.00 & 0.00 & 1,00 \\
\hline
\end{tabular}

UX, UY and RZ denote translational X direction, Y direction and Z-axis about the torsion mass participation factor.

Table 2.2 ETABS model and part hinged rigid model cycle before the six-order modes

\begin{tabular}{c|c|c|c|c|c|c|c|c}
\hline \multirow{2}{*}{ Modes } & \multicolumn{4}{|c}{ Articulated Model } & \multicolumn{3}{c}{ Part of the Rigid Model } \\
\cline { 2 - 9 } & Cycle (s) & UX & UY & RZ & Cycle (s) & UX & UY & RZ \\
\hline 1 & 2.2806 & $62.72 \%$ & $0.02 \%$ & $0.00 \%$ & 2.1879 & $62.75 \%$ & $0.02 \%$ & $0.00 \%$ \\
\hline 2 & 2.0664 & $0.02 \%$ & $64.10 \%$ & $0.00 \%$ & 2.0144 & $0.02 \%$ & $64.38 \%$ & $0.00 \%$ \\
\hline 3 & 1.1023 & $0.00 \%$ & $0.00 \%$ & $76.59 \%$ & 1.0478 & $0.00 \%$ & $0.00 \%$ & $76.59 \%$ \\
\hline 4 & 0.5170 & $1.94 \%$ & $18.34 \%$ & $0.00 \%$ & 0.5056 & $0.08 \%$ & $19.93 \%$ & $0.00 \%$ \\
\hline 5 & 0.5139 & $18.40 \%$ & $1.95 \%$ & $0.00 \%$ & 0.4921 & $20.13 \%$ & $0.08 \%$ & $0.00 \%$ \\
\hline 6 & 0.3911 & $0.00 \%$ & $0.00 \%$ & $11.36 \%$ & 0.3716 & $0.00 \%$ & $0.00 \%$ & $11.45 \%$ \\
\hline
\end{tabular}

UX, UY and RZ denote translational X direction, Y direction and Z-axis about the quality of the component involved in torsion.

Table 2.3 cycle ratio ( $\mathrm{T} 3$ / $\mathrm{T} 1)$

\begin{tabular}{c|c|c}
\hline Software & Articulated Model & Part of the Rigid Model \\
\hline SATWE & 0.524 & 0.584 \\
\hline ETABS & 0.483 & 0.478 \\
\hline
\end{tabular}

Thus, the first six vibration modes of the two models are basically the same, the first mode is for $\mathrm{X}$ to the translation, the second vibration mode are flat $\mathrm{Y}$ to move, can explain the structure of the $\mathrm{X}$-direction stiffness smaller than the $\mathrm{Y}$ direction. First-order and second-order vibration modes of the two models involved in component quality or less, and not more than $70 \%$, the first six vibration modes of mass participation component and not more than $90 \%$, indicating that the two models can not ignore the impact of higher modes. Compared with some rigid model, all articulated model of a larger cycle, indicating that all hinged model low stiffness. 


\section{Response Spectrum Analyses}

When the response spectrum analysis using CQC modal effect combinations, consider the impact of occasional eccentricity. The ratio of stiffness to weight of the structure results in Table 3.1.

Table 3.1 just heavier than

\begin{tabular}{c|c|c|c}
\hline Software & Direction & SATWE & ETABS \\
\hline Articulated & $\mathrm{X}$ & 8.38 & 8.60 \\
\cline { 2 - 4 } Model & $\mathrm{Y}$ & 9.69 & 9.90 \\
\hline Part of the & $\mathrm{X}$ & 8.82 & 9.14 \\
\cline { 2 - 4 } Rigid Model & $\mathrm{Y}$ & 10.02 & 10.22 \\
\hline
\end{tabular}

Just heavier than the two models are larger than 2.7, meet regulatory requirements, without considering the effect of the $P-\Delta$. Shear weight ratio (X direction) calculation results shown in Figure 3.1 and Figure 3.2.

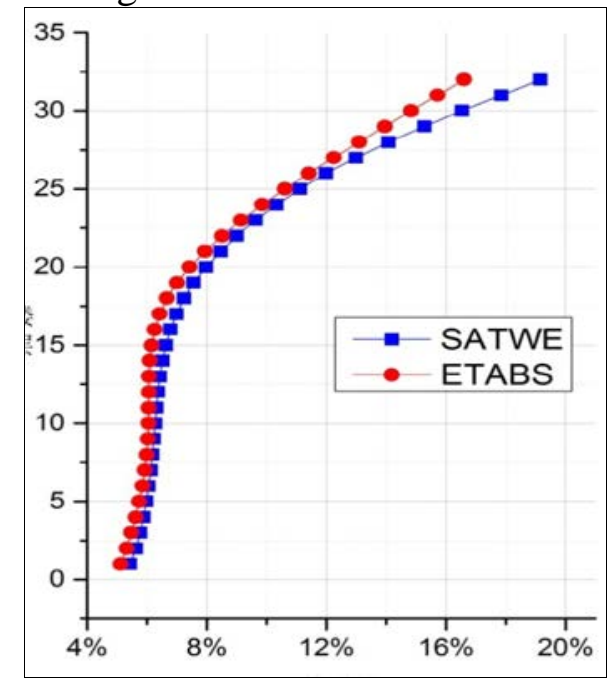

Figure 3.1 articulated model shear weight ratio

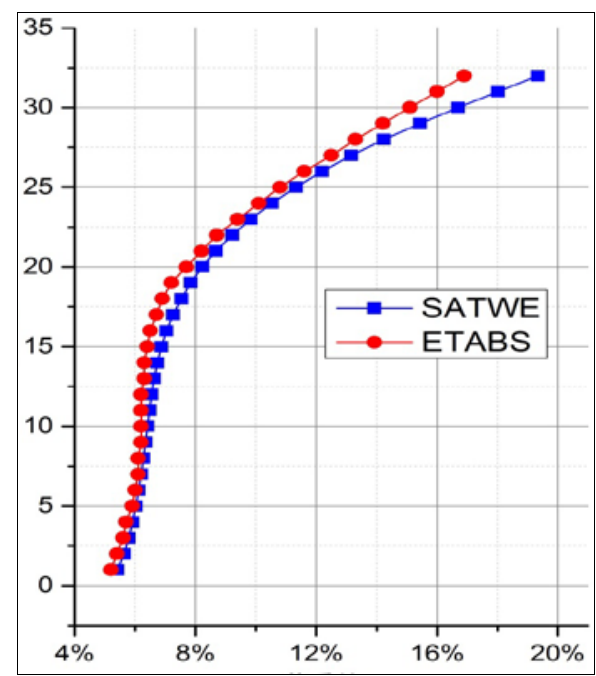

Figure 3.2 Rigid model shear weight ratio

Two models' shear-weight ratio were more than 3.2\%, indicating light weight structure and high stiffness, which is one of the advantages of hybrid structures. Since the shear stiffness contribution to the efficiency of the structure is higher than the frame column, so instead of the mixed results of the steel frame concrete frame for the loss of rigidity to compensate by shear walls, reducing the weight of the effect is significant.

After calculation and analysis, Interlayer displacement ratio and displacement ratio shown in Table 3.2.

Table 3.2 Model of the largest inter-storey drift angle and displacement ratio

\begin{tabular}{c|c|c|c|c}
\hline \multicolumn{2}{c|}{ Displacement } & Direction & SATWE & ETABS \\
\hline \multirow{4}{*}{$\begin{array}{c}\text { Articulated } \\
\text { Model }\end{array}$} & $\begin{array}{c}\text { Displacement } \\
\text { angle }\end{array}$ & $\mathrm{X}$ & $1 / 836$ (25th floor) & $1 / 803$ (26th floor) \\
\cline { 3 - 5 } & $\begin{array}{c}\text { Displacement } \\
\text { ratio }\end{array}$ & $\mathrm{Y} \pm 5 \%$ & $1 / 937$ (24th floor) & $1 / 879$ (24th floor) \\
\cline { 3 - 5 } & & $\mathrm{Y} \pm 5 \%$ & 1.17 (Layer 1) & 1.15 (Layer 1) \\
\hline \multirow{3}{*}{$\begin{array}{c}\text { Part of the } \\
\text { Rigid } \\
\text { Model }\end{array}$} & $\begin{array}{c}\text { Displacement } \\
\text { angle }\end{array}$ & $\mathrm{X}$ & $1 / 875$ (25th floor) & $1 / 829$ (26th floor) \\
\cline { 2 - 5 } & $\begin{array}{c}\text { Displacement } \\
\text { ratio }\end{array}$ & $\mathrm{X} \pm 5 \%$ & $1 / 974$ (22nd floor) & $1 / 909$ (24th floor) \\
\cline { 3 - 5 } & & $\mathrm{Y} \pm 5 \%$ & 1.18 (Layer 1) & 1.17 (Layer 1) \\
\hline
\end{tabular}

Thus, the inter-layer model all hinged displacement angle is greater than the parts of the rigid model, two less than the difference between the displacement models. Lateral stiffness of the entire model is smaller than the portion of the hinged rigid model, indicating that the steel beam and the core barrel hinge on a smaller contribution of lateral stiffness, floor beams and the core barrel section can be improved lateral performance rigid structure, but the connection in the form of 
torsion little effect.

In high intensity regions, a question existence of the steel frame-core tube structure is a very low percentage of shear and overturning moment undertaken outside the framework, such as a second line of defense, steel frame press the "maximum shear frame sections 1.8 earthquake times "Design is too small, such as by "25\%at the bottom of the structure of the overall shear" design of the frame parts have a greater increase in the amount of steel, and the relevant analysis and tests have shown that rare earthquake frame column mostly do not yield, the withstand seismic forces also cannot reach $25 \%$ of the total shear structure at the bottom.

Table 3.3 response spectrum method underlying frame column base shear and overturning moment assume the percentage

\begin{tabular}{c|c|c|c|c|c}
\hline Model & Software & X base shear & Y base shear & $\begin{array}{c}\text { X overturning } \\
\text { moment }\end{array}$ & $\begin{array}{c}\text { Y overturning } \\
\text { moment }\end{array}$ \\
\hline $\begin{array}{c}\text { Articulated } \\
\text { Model }\end{array}$ & SATWE & $7.05 \%$ & $9.14 \%$ & $15.46 \%$ & $13.12 \%$ \\
\cline { 2 - 6 } $\begin{array}{c}\text { PTABS } \\
\begin{array}{c}\text { Rigid } \\
\text { Model }\end{array}\end{array}$ & SATWE & $7.67 \%$ & $9.65 \%$ & $13.11 \%$ & $15.05 \%$ \\
\cline { 2 - 6 } & ETABS & $6.50 \%$ & $8.74 \%$ & $16.06 \%$ & $13.93 \%$ \\
\hline
\end{tabular}

As can be seen from Table 3.3, the underlying framework than most assumed earthquake and seismic shear and overturning moment of the total seismic shear layer is less than $10 \%$, more than the total seismic overturning moment is less than $18 \%$. Bear the other layers shear is not more than $12 \%$, moment frame columns assume the proportion overturning increases as the number of layers increases, the top frame portion may reach about 54\%. For this structural model, both rigid connection part and the entire hinge, there is a problem of a small frame portion shear assumed.

\section{Conclusions}

1. Hinged model with some dynamic characteristics of the model are basically the same rigid, articulated model displacement ratio of less than part of the rigid model, reversing the effects of rigid model described in the earthquake slightly larger than the occasional eccentric hinge model.

2. Steel beams form the core tube connection modes have little effect on the structure, but the larger cycle impact on the structure, steel beams and rigid core barrel can increase the lateral stiffness of the structure, reducing the lateral displacement of the structure.

3. Steel beams and connections form the core tube torsion effect has little effect on the structure, but because of the stiffness of the frame part is small, its contribution to the stiffness of the whole structure is also smaller, connected in the form of rigid or articulated matter, have had to bear part of the frame cut little impact force and overturning moment.

\section{References}

[1]Ying Liu, Songtao Wang, Ning Zhao IN STEEL Steel-research combination of seismic performance of concrete core barrel [J]. Engineering Mechanics, 1999 (supply).

[2]Liusheng Chu, Guoliang Bai, Gengqi Zhao, Junfeng Zhang. High intensity area of steel reinforced concrete frame - core concrete tube failure mode hybrid structure [J]. Industrial buildings, 2010, 40 (5).

[3]Chen W F, Lui E M. Stability design of steel frames [M]. CRC press, 1991.

[4]Kim Y, Chen W F. Practical analysis for partially restrained frame design [J]. Journal of structural Engineering, 1998, 124(7): 736-749.

[5]People's Republic of China Ministry of Housing and Urban GB50011-2010 seismic design of buildings [S] Beijing: China Building Industry Press, 2010.8 